\section{THE CONCENTRATION OF UREA IN SALIVA *}

\author{
PHILIP S. HENCH, B.A., M.D. \\ Fellow in Medicine, Mayo Foundation \\ AND \\ MARTHA ALDRICH, B.A. \\ ROCHESTER, MINN.
}

In order to determine whether the concentration of urea in the saliva is of clinical importance in the diagnosis and prognosis of nephritis, quantitative urea estimations were made on the saliva of a small group of nephritic patients under observation at the Mayo Clinic during the last three months. The quantitative excretion of urea in the urine and its concentration in the blood have been studied extensively. Various observers have recognized that urea is excreted in the sweat, gastric juice, feces and saliva of nephritic and uremic patients; but such work has consisted mainly in qualitative estimations, and few quantitative estimations are on record.

Schöndorff ${ }^{1}$ has given a comprehensive review of the early work on this subject. Pettenkoffer ${ }^{2}$ and Wright ${ }^{2}$ were the first to note that urea is present in appreciable amounts in the saliva of healthy persons and in patients with nephritis. Later, many isolated quantitative estimations were made by Picard, ${ }^{2}$ Poisseuille, ${ }^{2}$ Bechamp, ${ }^{2}$ Gréhant ${ }^{2}$ and others; but the inexact method of their day (the sodium hypobromite method) gave data, some of which are unreasonable in the light of modern technic. In individual instances, however, Picard and Gréhant found $35 \mathrm{mg}$. of urea per hundred cubic centimeters, and Bechamp 30 . Fleischer ${ }^{2}$ did not recover urea from the saliva of a healthy person after pilocarpin administration; but he demonstrated its presence in the saliva of persons suffering from nephritis. Debove and Dreyfous ${ }^{3}$ obtained $5 \mathrm{gm}$. of urea in 400 c.c. of saliva from a uremic patient after the injection of pilocarpin.

$\mathrm{Kyle}^{4}$ and Le Roy ${ }^{5}$ have made observations of clinical importance with regard to the chemistry of saliva in normal persons. Herzfeld and Stocker ${ }^{6}$ have studied the presence of uric acid in saliva. Anrep, ${ }^{7}$ Wolf and Barcroft ${ }^{8}$ have carried out metabolic studies on the salivary glands of animals. With these exceptions, the metabolism of the salivary gland and the chemistry of saliva are given little consideration in the literature.

We have constantly found a certain amount of nitrogen in the saliva of man, which we believe to be derived wholly or mainly from urea. The amount of urea in the saliva bears a very close relationship to the

* From the Division of Medicine, Mayo Clinic and Mayo Foundation, Rochester, Minn. Similar studies have been carried out on the gactric contcits of a like group of persons, and the results will be published in a subsequent paper. Quantitative studies of salivary creatinin are also eing attempted, with rather unsatisfactory results.

1. Schöndorff, B.: Die Harnstoffvertheilung im thierischen Organismus und das Vorkommen des Harnstoffs im normalen Säugethiermuskel, Arch. f. d. ges. Physiol. 7 4: 307-356, 1899.

2. Quoted by Schöndorff (Footnote 1). 3. Debove and Dreyfous, quoted by pathologie, Paris, Masson et Cie, 1912.

4. Kyle, D. B.: Chemistry of Saliva in Relation to Hay-Fever, J. A M. A. 49: $402-406$ (Aug. 3) 1907 .

5. Le Roy, B. R.: Colorimetric Analysis of the Saliva, with the Clinical Significance, New York M. J. 87: 448-450, 1903.

6. Herzfeld, E., and Stocker, A.: Ueber das Vorkommen von Harn säure im normalen und pathologischen Speichel, Zentralbl. f. inn. Med. 34: $753-757,1913$.

7. Anrep, G. V.: The Metabolism of the Salivary Glands. I. The Relation of the Chorda Tympani to the Nitrogen, J. Physiol. 54: 319 . 331 (March) 1921.

8. Wolf, C. G. L., and Barcroft, J.: The Metabolism of the Salivary Gland. I. The Nitrogen Metabolism of the Resting Gland, J. Physiol. amount of urea in the blood. This suggests that urea reaches the saliva by diffusion, and the physical properties of urea are such that its diffusion is to be expected.

Anrep considered the saliva as both a specific and a nonspecific excretion. The specific fraction contained mucin nitrogen, while the nonspecific fraction contained nonmucin nitrogen. As electrical stimulation of the chorda tympani of a dog progresses, the total nitrogen diminishes, the specific excretion, which includes mucin nitrogen, soon becomes exhausted, and the nonmucin nitrogen fraction alone continues (Chart 1). Anrep determined that the excretion of the nonmucin nitrogen, which remained constant, was independent of the mucin nitrogen. This was in accord with the studies of Pavlov, ${ }^{9}$ and in contradistinction to the views of Heidenhain ${ }^{9}$ and Langley, ${ }^{9}$ who believed that the turn-

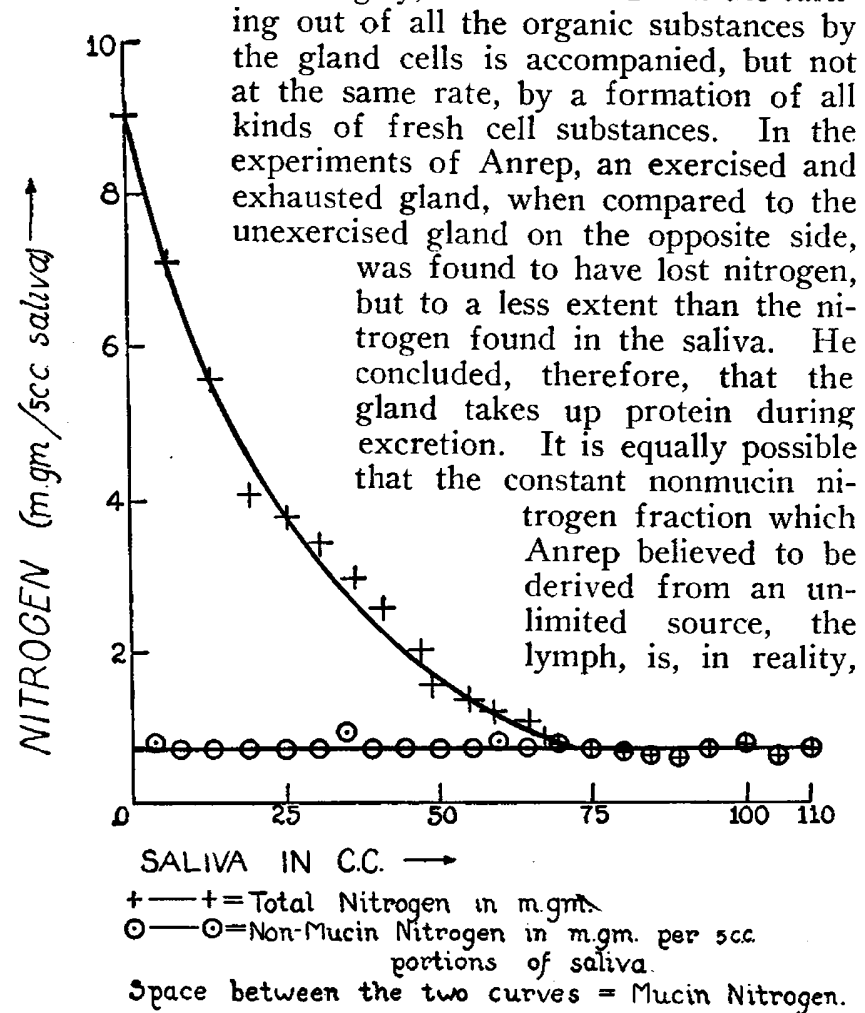

Chart 1.-Salivary gland metabolism (from Anrep).

urea constantly passing as such from the blood to the saliva. Our experiments support the latter view.

We have centered attention on the combined urea and ammonia nitrogen value, which will be referred to as the combined nitrogen. That combined nitrogen is the proper basis for comparison is obvious, since if the urea nitrogen only is computed, an inconstancy of values is inevitable, owing to the tendency of urea to hydrolyze rapidly into ammonium carbonate. In individual cases, subtraction of the free ammonia nitrogen from the combined nitrogen often reduces the urea nitrogen to a trace, whereas our experiments show that in these cases the ammonia nitrogen is derived largely or entirely from urea. Factors influencing the amount of urea breakdown are the length of time the saliva has remained in the gland, and the hygiene of the mouth. It has been noted by Le Roy and others that there is more ammonia in a filthy, than in a clean, mouth. Since the urea values, as determined, are

9. Quoted by Anrep (Footnote 7). 
likely to be misleading and inconstant, the combined nitrogen values are considered as the index and basis of comparison, as the fulcrum on which the ammonia and urea values change in the process of urea hydrolysis.

\section{TECHNIC ' AND FINDINGS}

The determinations of ammonia and urea nitrogen were made by the urease method of $\cdot$ Marshall, ${ }^{10}$ and of Van Slyke and Cullen. ${ }^{11}$ Chart 2 is the curve of salivation for one hour in a patient with urea retention. In it is contrasted the marked variation in the estimated urea values with the relative constancy, of the combined nitrogen values. Table 1 also demonstrates this point. In Case 9, there was only a trace of urea nitrogen, whereas the combined nitrogen was a high normal value.

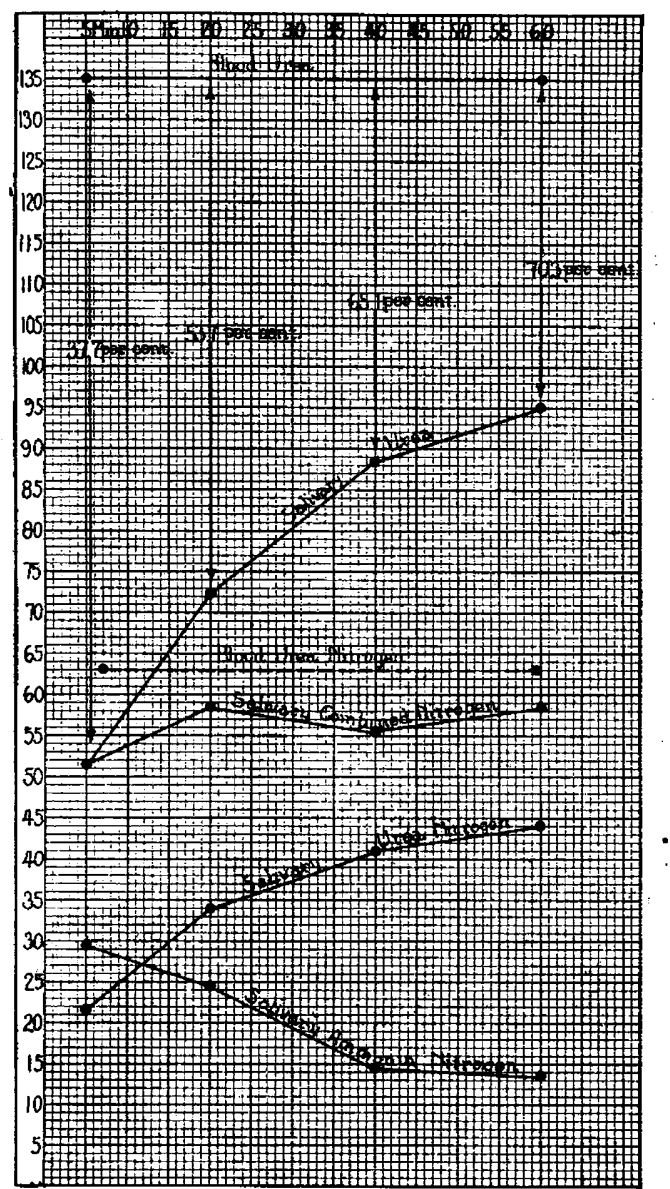

Chart 2.-Curve of salivation for one hour in a patient with urea retention. The figures represent nilligrams for each hundred cubic centimeters.

Table 2 indicates that the ammonia nitrogen in the saliva is derived from urea. In the saliva from an unwashed mouth the ammonia nitrogen fraction is high, as the saliva has been acted on by urea-splitting agents, such as bacteria, while, after the mouth has been washed, the ammonia nitrogen fraction is low. In both the washed and the unwashed mouth, the combined nitrogen values are practically constant and within normal limits.

According to the data in Table 3, there is no exhaustion of the combined nitrogen fraction of the

10. Marshall, E. K., Jr.: A New Method for the Determination of Urea in Blood, J. Biol. Chem. 15: 487-494, 1913.

11. Van Slyke, D. D., and Cullen, G. E.: A Permanent Preparation of Urease and Its Use in the Determination of Urea, J. Biol. Chem. 19: $211-228,1914$. salivary excretion, and there is no factor of dilution as salivation progresses. Table 4 demonstrates that the administration of pilocarpin does not change the constancy of the combined nitrogen or introduce dilution factors. Table 5 again emphasizes the constancy of the combined nitrogen value. On allowing the saliva to stand outside the mouth for a short time, little change

$\begin{array}{rrrrr}\text { TABLE 1.-CONSTANCY OF COMBINED UREA AND } & \text { AMMONIA } \\ \text { NITROGEN VALUES AND INCONSTANCY } & \text { OF UREA } \\ \text { OFALUES } \\ \text { OF THE SALIVA OF NORMAL } \\ \text { PERSONS }\end{array}$

in the various normal values is obtained. When, however, it remains outside the mouth for several hours, the urea may be split; the urea nitrogen value is lowered to the profit of the ammonia nitrogen, but the combined reading remains constant.

TABLE 2.-EFFECT OF ORAL HYGIENE ON AMMONIA NITLO GFN, UREA NITROGEN AND UREA VALUES OF THE SALIVA: SALIVARY PERIODS ONE HOUR EACH

\begin{tabular}{|c|c|c|c|c|c|c|c|c|}
\hline & & Iouth Not & Washed & & & Mouth W & $\nabla$ ashed & \\
\hline $\begin{array}{l}\text { Time, } \\
\text { Min- } \\
\text { utes }\end{array}$ & $\begin{array}{c}\text { Am- } \\
\text { monia } \\
\text { Nitro- } \\
\text { gen, } \\
\text { Mg. for } \\
\text { Each } \\
\text { 100 C.c. }\end{array}$ & $\begin{array}{c}\text { Combined } \\
\text { Ammonia } \\
\text { and Urea } \\
\text { Nitro- } \\
\text { gen, } \\
\text { Mg. for } \\
\text { Each } \\
100 \text { C.c. }\end{array}$ & $\begin{array}{l}\text { Urea } \\
\text { Nitro- } \\
\text { gen, } \\
\text { Mg. for } \\
\text { Each } \\
\text { 100 C.c. }\end{array}$ & $\begin{array}{c}\text { Urea, } \\
\text { Mg. for } \\
\text { Each } \\
100 \text { C.c. }\end{array}$ & $\begin{array}{c}\text { Am- } \\
\text { monia } \\
\text { Nitro- } \\
\text { gen, } \\
\text { Mg. for } \\
\text { Each } \\
\text { 100 C.c. }\end{array}$ & $\begin{array}{l}\text { Combined } \\
\text { Ammonia } \\
\text { and Urea } \\
\text { Nitro- } \\
\text { gen, } \\
\text { Mg. for } \\
\text { Each } \\
100 \text { C.c. }\end{array}$ & $\begin{array}{c}\text { Urea } \\
\text { Nitro- } \\
\text { gen, } \\
\text { Mg. for } \\
\text { Each } \\
\text { 100 C.c. }\end{array}$ & $\begin{array}{c}\text { Urea. } \\
\text { Mg.f r } \\
\text { Each } \\
\text { 100.C.c. }\end{array}$ \\
\hline $\begin{array}{r}5 \\
10 \\
20 \\
40 \\
60\end{array}$ & $\begin{array}{l}8.34 \\
8.0 \\
4.48 \\
2.94 \\
2.24\end{array}$ & $\begin{array}{l}9.24 \\
8.84 \\
9.24 \\
8.82 \\
9.2\end{array}$ & $\begin{array}{l}0.9 \\
0.84 \\
4.76 \\
5.88 \\
6.96\end{array}$ & $\begin{array}{c}1.92 \\
1.8 \\
10.2 \\
12.6 \\
14.8\end{array}$ & $\begin{array}{l}1.62 \\
1.62 \\
0.84 \\
1.9 \\
1.7\end{array}$ & $\begin{array}{l}6.72 \\
8.1 \\
7.0 \\
8.0 \\
7.76\end{array}$ & $\begin{array}{l}5.1 \\
6.48 \\
6.16 \\
6.1 \\
6.06\end{array}$ & $\begin{array}{l}10.9 \\
13.93 \\
13.2 \\
13.0 \\
12.95\end{array}$ \\
\hline
\end{tabular}

Estimation of the Salivary Combined Nitrogen of Normal Persons (Chart 3).--Sixty-four estimations of the combined nitrogen of the saliva were made on healthy persons without any relation to meals or oral hygiene. Sixty-two estimations fell between 6 and 13

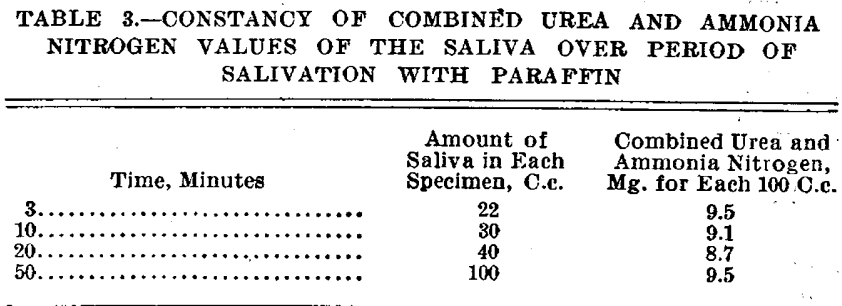

mg. One abnormally low and one abnormally high value were encountered, which may possibly have been due to technical error.

Estimation of the Combined Urea and Ammonia Nitrogen in the Saliva of Nephritic Patients (Chart 4). -Forty combined nitrogen estimations were made on the saliva of patients with urea retention. The icombined nitrogen value was constantly above $13 \mathrm{mg}$., with one exception, in which the reading was $13 \mathrm{mg}$.

The Relation Between the Combined Nitrogen and the Blood Urea Nitrogen Values of the Saliva: of 
Treenty-Four Persons (Chart 5).-This curve shows that in all persons who had a normal blood urea nitrogen value, $16 \mathrm{mg}$. or less for each hundred cubic centimeters, the combined nitrogen of the saliva was less than $13 \mathrm{mg}$. for each hundred cubic centimeters. However, as soon as urea retention is evidenced by a rise in blood urea nitrogen above $16 \mathrm{mg}$. for each hundred cubic centimeters, the combined nitrogen value of the saliva also ascends in a curve which shows a tendency to follow the blood urea nitrogen curve. More data on comparative estimations are necessary in order to determine the exact relationship between the two curves. Two estimations are apparently abnormally high. The mouths of both patients were very filthy and the increased ammonia may have been due to pollution.

TABLE 4.-CONSTANCY OF COMBINED UREA AND AMMONIA NITROGEN VALUES OF THE SALIVA WITH ACTION OF PILOCARPIN, ONE-FIFTH GRAM BY MOUTH

\begin{tabular}{|c|c|c|}
\hline . Tinle, Minutes & $\begin{array}{l}\text { Amount of } \\
\text { Saliva in Each } \\
\text { Specimen, C.c. }\end{array}$ & $\begin{array}{l}\text { Combined Urea and } \\
\text { Ammonia Nitrogen, } \\
\text { Mg. for Each } 100 \text { C.c. }\end{array}$ \\
\hline 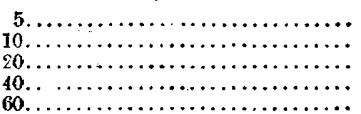 & $\begin{array}{l}10 \\
20 \\
32 \\
60 \\
65\end{array}$ & $\begin{array}{l}7.8 \\
6.5 \\
7.5 \\
7.2 \\
7.7\end{array}$ \\
\hline
\end{tabular}

POSSIBLE SOURCES OF ERROR

In most of the estimations, the saliva was collected without any relation to meals or oral hygiene. Nevertheless, the constancy of results speaks against any great source of error on this account. In future investigation, it would be well to improve the technic as follows: The patient should be required to rinse the mouth well with water or dilute acetic acid, and

TABLF 5-EFFECT OF ALLOWING SALIVA TO STAND A'T ROOM TTEMPERA'TURE FOR TWO, FIVE AND EIGHT HOUR PERIODS *

\begin{tabular}{|c|c|c|c|c|}
\hline $\begin{array}{ll}\text { Case } & \text { Time }\end{array}$ & $\begin{array}{c}\text { Am- } \\
\text { monia } \\
\text { Nitro- } \\
\text { gen, } \\
\text { Mg. for } \\
\text { Each } \\
100 \text { C.e. }\end{array}$ & $\begin{array}{c}\text { Combin̉ed } \\
\text { Ammonia } \\
\text { and Urea } \\
\text { Nitro- } \\
\text { gen, } \\
\text { Mg. for } \\
\text { Each } \\
100 \text { C.c. }\end{array}$ & $\begin{array}{l}\text { Urea } \\
\text { Nitro- } \\
\text { gen, } \\
\text { Mg. for } \\
\text { Each } \\
\text { 100 C.c. }\end{array}$ & $\begin{array}{c}\text { Urea, } \\
\text { Mg. for } \\
\text { Each } \\
100 \text { C.c. }\end{array}$ \\
\hline Normal......Immediately................. & $\begin{array}{l}0.98 \\
2.66\end{array}$ & $\begin{array}{l}6.44 \\
8.5\end{array}$ & $\begin{array}{l}5.46 \\
5.84\end{array}$ & $\begin{array}{l}11.7 \\
12.5\end{array}$ \\
\hline Normal...... Immediately................ & $\begin{array}{l}5.67 \\
6.3\end{array}$ & $\begin{array}{l}8.71 \\
9.38\end{array}$ & $\begin{array}{l}3.64 \\
3.08\end{array}$ & $\begin{array}{l}7.7 \\
6.1\end{array}$ \\
\hline Nephritic.... Immediately............... & $\begin{array}{l}13.3 \\
27.7\end{array}$ & $\begin{array}{l}29.7 \\
30.8\end{array}$ & $\begin{array}{r}16.4 \\
3.1\end{array}$ & $\begin{array}{r}35.0 \\
6.7\end{array}$ \\
\hline
\end{tabular}

* A slight increase in the combined ammonia and urea nitrogen values is noted after standing. It is possible that other reactions than that of

to chew paraffin. After two or three minutes, about 25 c.c. of saliva should be collected, filtered through three or four thicknesses of gauze, and estimations made on 5 c.c. of the filtrate, neutralized approximately to methyl red.

Any extraneous sources of ammonia other than that from the saliva would increase the combined nitrogen value. $^{12}$ Such sources might be a filthy mouth and tobacco smoke, which contains a small amount of ammonia. Any substance, such as mercuric chlorid in the mouth wash or tooth paste, which might retard or destroy the action of the urease, would appear to lower the combined nitrogen value, since the fraction of urea failing to undergo hydrolysis would be missed.

12. Vaubel, W.: Ammonia Content of Tobacco Smoke, Chem. Abstr. 6: 667,1912 .
The excretion of ammonia by the lungs may be disregarded. Experiments by Weisman, ${ }^{13}$ Amoss, ${ }^{14}$ Rosenau and Amoss, ${ }^{15}$ and Krogh ${ }^{16}$ show that there is no urea excreted by the lungs and only a faint trace of ammonia, if any. On analyzing the condensation liquid collected from five hours of respiration, Amoss recovered only $1.9 \mathrm{mg}$. of organic matter, all of which

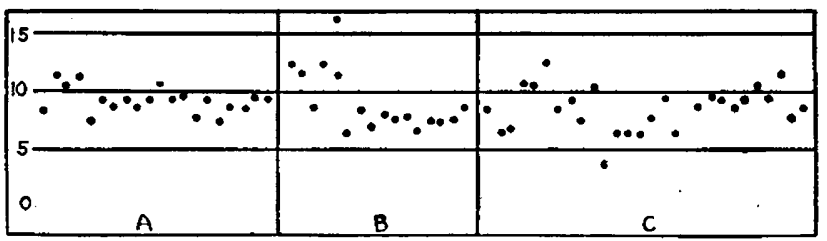

Chart 3.-Estimation of the salivary combined nitrogen of normal persons: $A$, twenty observations of combined nitrogen, in a normal person, over a period of three months; $B$, seventeen observations of combined nitrogen, in a normal person, over, a period of three months; $C$, twenty-seven observations of combined nitrogen, in different normal persons.

he considered to be ammonia. Even so, it is questionable whether the ammonia thus obtained was from droplets of saliva, or from nasal excretion.

\section{POSSIBLE THERAPEUTIC IMPORTANCE OF FINDINGS}

Whether salivation as a therapeutic procedure may ever become of value in urea retention is uncertain Values as high as $338 \mathrm{mg}$. of urea for each hundred cubic centimeters of saliva have been obtained. In many cases, it has been possible to salivate patients to the extent of 200 c.c. of saliva each hour, showing that from 3 to $4 \mathrm{gm}$. of urea can be disposed of by this

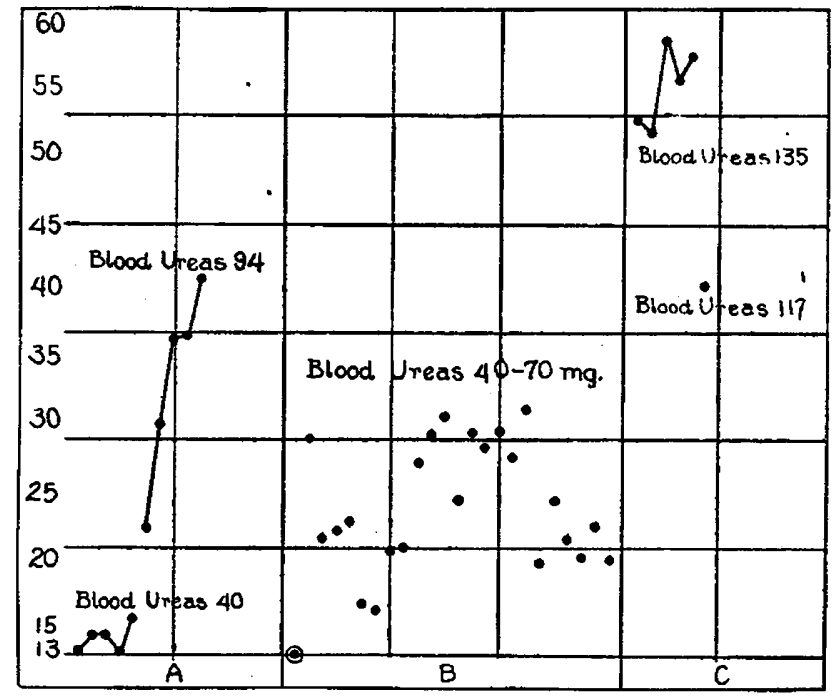

Chart 4.-Estimation of the combined urea and ammonia nitrogen in the saliva of nephritic patients: $A$, the same patient at different periods; $B$, twenty-four different nephritic patients; $C$ six observations on two nephritic patients. The figures represent milligrams for each hundred cubic centimeters.

method during the day. This is a considerable amount, since, in certain cases of uremia, no more than this is excreted by the urine. Prolonged salivation, which is

13. Weisman, C.: Biochemical Studies of Expired Air in Relation to Ventilation, Biochem. Bull. $2: 558,1912-1913$.

14. Amoss, H. L.: Organic Matter in the Expired Breath with Especial Reference to Its Inhibiting Power on Oxidizing Ferments, J. Exper. Reference to Its Inhibitin
Med. 1r: $132-151,1913$.

15. Rosenau, M. J., and Amoss, H. L.: Organic Matter in the Expired Breath, J. Med. Res. 25: 35-84, 1911-1912.

Breath, J. Med. Res. 25: 35-84, 1911-1912. 16. Krogh, A.: Experimental Researches on the Expiration of Free
Nitrogen from the Body, Skandin. Arch. f. Physiol. 18: 364-420, 1906. 
often aggravated in those patients to whom it might be of real value, is, however, so incommodious that its use therapeutically is questionable.

\section{CONCLUSIONS}

1. The results thus far obtained in normal persons indicate that the combined urea and ammonia nitrogen values of the saliva are normally between 6 and $13 \mathrm{mg}$. for each hundred cubic centimeters, representing between 13 and $27 \mathrm{mg}$. of urea for each hundred cubic centimeters. The combined urea and ammonia nitrogen values of the saliva closely approximate those of the urea nitrogen of the blood.

2. In urea retention, the combined urea and ammonia nitrogen of saliva always increases with an increase in the blood urea nitrogen.

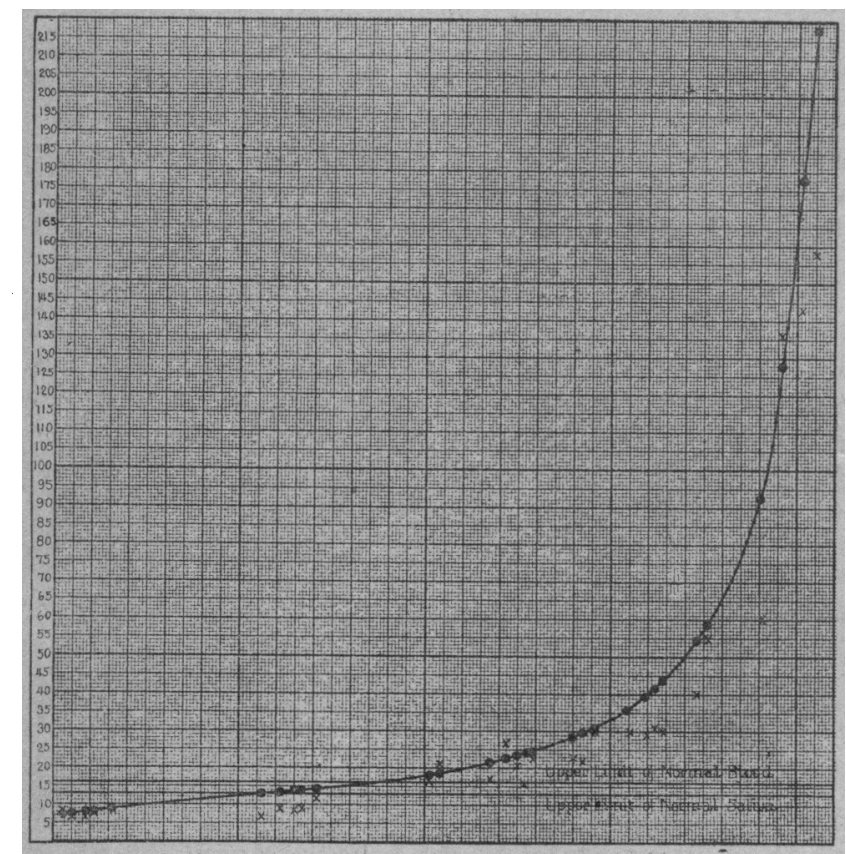

Chart 5.-Relation between the combined nitrogen and the blood urea nitrogen values of the saliva of twenty-four persons. The figures rcpresent milligrams for each hundred cubic centimeters.

3. The combined nitrogen of saliva is a valuable index of renal functional capacity.

4. The determination of the combined nitrogen of saliva may precede or replace blood urea nitrogen determinations, especially in children and other persons difficult to bleed. The finding of a normal combined nitrogen value in the saliva excludes the possibility of an abnormal blood urea value. High combined nitrogen values in the saliva indicate the need of studies of the blood.

Child Care in Rural Communities.-In a report just issued by the U. S. Department of Labor through the Children's Bureau, entitled "County Organization for Child Care and Protection," the most recent administrative advances in the local care of dependent, defective and delinquent children are described. It is stated that care for these children by local boards of citizens, employing trained workers and aided by state boards, is gaining approval in an increasing number of states. The greatest difficulty about these organizations is securing executives trained for such work, it is stated. State universities, now, however, are preparing students to return to their home communities and take up this career, and state boards make possible the interchange of experience through conferences, publications and other means.

\section{CENTRAL RETINITIS WITH RECOVERY OF NORMAL VISION *}

\author{
W. H, LUEDDE M.D. \\ AND \\ J. F. HARDESTY, M.D.
} ST, LOUIS

Retinal inflammations incident to serious constitutional diseases have been of interest to general practitioners and ophthalmologists ever since the invention of the ophthalmoscope made their observation and study possible. The importance justly attributed to the early recognition of such lesions has not been due primarily to the possibility of saving eyesight but rather their significance in the diagnosis and prognosis of the general malady.

Not infrequently an active and apparently healthy person, aroused by an impairment of vision, shows on ophthalmoscopic examination such characteristic lesions that the oculist is almost enabled to name the disease and predict the outcome. Unfortunately, the treatment then undertaken by the internist or family physician may be limited to belated and more or less hopeless efforts to save life. The loss of eyesight which gave the first warning naturally becomes quite a secondary matter. Perhaps an exception shauld be noted among cases of threatened blindness due to albuminuric retinitis of pregnancy. Under these circumstances the induction of premature labor with sacrifice of the immature fetus to save the mother's eyesight has been performed and may be fully justified. However, it is not only the eyesight of the mother but the danger to her life as well which demands this procedure.

The purpose of this report is to emphasize the possibility of saving eyesight by accurate diagmosis and prompt and proper treatment when the retinitis is due to certain localized infections and is not actually caused by a constitutional disease which may happen to be present or suspected.

Neither the presence of glycosuria nor albuminuria precludes the possibility that the retinal lesion may be caused by a focal infection. In fact, it appears in two cases here reported that the glycosuria and albuminuria, as well as the ocular lesion, were due to the focal infection.

With reference to the relation between localized infections and ocular tuberculosis, personal clinical observations seem to justify two conclusions: (1) A focal reaction in certain nasal sinuses occurs simul. taneously with the focal ocular reactions in most cases after hypodermic test injections of tuberculin; (2) radical treatment of the focal infections in the nose or throat is followed by control and cure of the ocular lesion.

This applies as well to the more frequent lesions of the uveal tract or cornea as to those of the retina. So satisfactory has been the result of the immediate elimination of focal infections, such as diseased tonsils and infected sinuses accompanying these tuberculous ocular lesions, that the therapeutic use of tuberculin has rarely been required.

When syphilis is known to be present, there is a strong tendency to attribute all local ocular disease to

* Read before the Section on Ophthalmology at the Seventy Thir Annual Session of the American Medical Association, St. Louis, May, 